\title{
Preoperative serum vascular endothelial growth factor correlated to three dimensional power Doppler indices in ovarian masses
}

\author{
Maged R. AbouSeeda ${ }^{1}$, Ghada M. Mansour ${ }^{1 *}$, Sahar S. Ez-Elarab ${ }^{2}$ \\ ${ }^{1}$ Department of Obstetrics and Gynecology, Ain Shams University, Cairo, Egypt \\ ${ }^{2}$ Early Cancer Detection Unit, Maternity Hospital, Ain Shams University, Cairo, Egypt \\ Email: "gmansour@hotmail.com
}

Received 8 January 2014; revised 6 February 2014; accepted 14 February 2014

Copyright (C) 2014 Maged R. AbouSeeda et al. This is an open access article distributed under the Creative Commons Attribution License, which permits unrestricted use, distribution, and reproduction in any medium, provided the original work is properly cited. In accordance of the Creative Commons Attribution License all Copyrights (C) 2014 are reserved for SCIRP and the owner of the intellectual property Maged R. AbouSeeda et al. All Copyright (C) 2014 are guarded by law and by SCIRP as a guardian.

\section{ABSTRACT}

Objective: To assess the preoperative serum levels of vascular endothelial growth factor (VEGF) in ovarian masses compared to normal controls and to find a correlation between VEGF and Doppler indices in ovarian masses. Methods: The study was conducted from December 2009 to September 2012 in the oncology and ultrasound units in department of obstetrics and gynecology, Ain Shams University on 150 patients with ovarian masses. During preoperative workup, serum Ca-125 levels and serum VEGF levels were obtained. Ultrasonographic examination included two and three dimensional power Doppler ultrasound (3DPD). Laparotomic approaches were undertaken to obtain the final pathologic results. VEGF was measured in one hundred normal cases as controls. Results: Final ovarian pathology revealed seventy three malignant ovarian masses and seventy seven were benign. Serum Ca-125 levels in malignant cases were higher compared to those in benign cases $(p<0.001)$. Preoperative serum VEGF revealed higher levels in malignant ovarian masses than benign conditions and normal controls $(p<0.001)$. Three dimensional power Doppler indices, vascularization index (VI), flow index (FI) and vascularization flow index (VFI), correlated positively with serum VEGF levels. Conclusion: Preoperative serum VEGF revealed higher levels in malignant ovarian masses than benign conditions and normal controls. These levels positively correlated with the Doppler vascular indices of the masses.

\footnotetext{
${ }^{*}$ Corresponding author.
}

\section{KEYWORDS}

Ovarian Cancer; Ovarian Mass; Three Dimensional Power Doppler; VEGF; VI; FI; VFI

\section{INTRODUCTION}

Ovarian cancer was the third most frequent gynecological neoplasm and corresponded to the highest mortality rate in developed countries [1].

Vascular endothelial growth factor (VEGF) is a signal protein produced by cells that stimulate vasculogenesis and angiogenesis. It is part of the system that restores the oxygen supply to tissues when blood circulation is inadequate. [2] When VEGF is overexpressed, it can contribute to disease. Solid cancers can not grow beyond a limited size without an adequate blood supply; cancers that can express VEGF are able to grow and metastasize.

Angiogenesis has a vital role in tumor growth and metastasis, and vascular endothelial growth factor (VEGF) represents a potent cytokine in this process [2].

Three dimensional power Doppler is a rather new modality for assessment of the vascularity of an organ or mass. The degree of arborization of different vessels in a mass can be assessed by the vascular indices VI, FI and VFI.

Using three dimensional power Doppler in assessment of vascularity of ovarian masses revealed its sensitivity in prediction of ovarian malignancy, [3] and adding 3DPD to the risk of malignancy index increased its sensitivity for prediction of ovarian malignancy [4].

The vascular indices, vascularization index (VI), vascularization flow index (VFI), and flow index (FI) are expressing the degree of vascularity of an organ in the 


\section{D data set.}

The aim of this study was to compare the preoperative serum levels of vascular endothelial growth factor (VEGF) in ovarian masses with normal controls and to find a correlation between VEGF and Doppler indices in ovarian masses.

\section{SUBJECTS AND METHODS}

The study was conducted on 150 patients with ovarian masses.

During preoperative workup, complete history was taken from all patients including age, marital status, occupation and special habits.

Medical ethics committee approval and consent from every patient were obtained.

Cases with associated medical disorders as vascular diseases, autoimmune disorders, causes for bleeding tendency or patients on anticoagulant therapy were all excluded from the study.

General and local examinations were done for all cases.

Preoperative serum Ca-125 levels and serum VEGF levels were estimated for all cases and ultrasonographic examination of the masses were done.

Serum VEGF was measured by ID ELISA tm Human VEGF Elisa kits VEGF kits were ordered from ID labs-
Canada (www.Idlabs.com).

(IDEL-V-Enzyme Immunoassay for the Detection of Human VEGF in Cell Culture Supernatants, Serum, and Plasma).

Ultrasonographic scans included depiction of the uterus and both ovaries by both transvaginal and abdominal approaches.

The assessment of the masses by ultrasound included comment on consistency of the mass, wall thickness, bilaterality and presence of ascites and/or focal lesions of the liver.

Doppler ultrasound included 2D Doppler blood flow resistance index (RI) of the blood flow of the mass and three dimensional power Doppler indices of the masses including VI, FI and VFI.

Two dimensional Doppler ultrasound was introduced and sample volume was focused on the intra-tumeral vessels and resistance index (RI) was calculated.

After introduction of 3DPD, the gate was centralized on the most vascular area of the mass. After acquisition of the volume, and 3D multiplanar view was obtained, histogram program was activated and vascular indices were calculated. (Figure 1) All ultrasound and Doppler scans were done by the same person, the second author.

Laparotomic approaches were undertaken to obtain the final pathologic results.

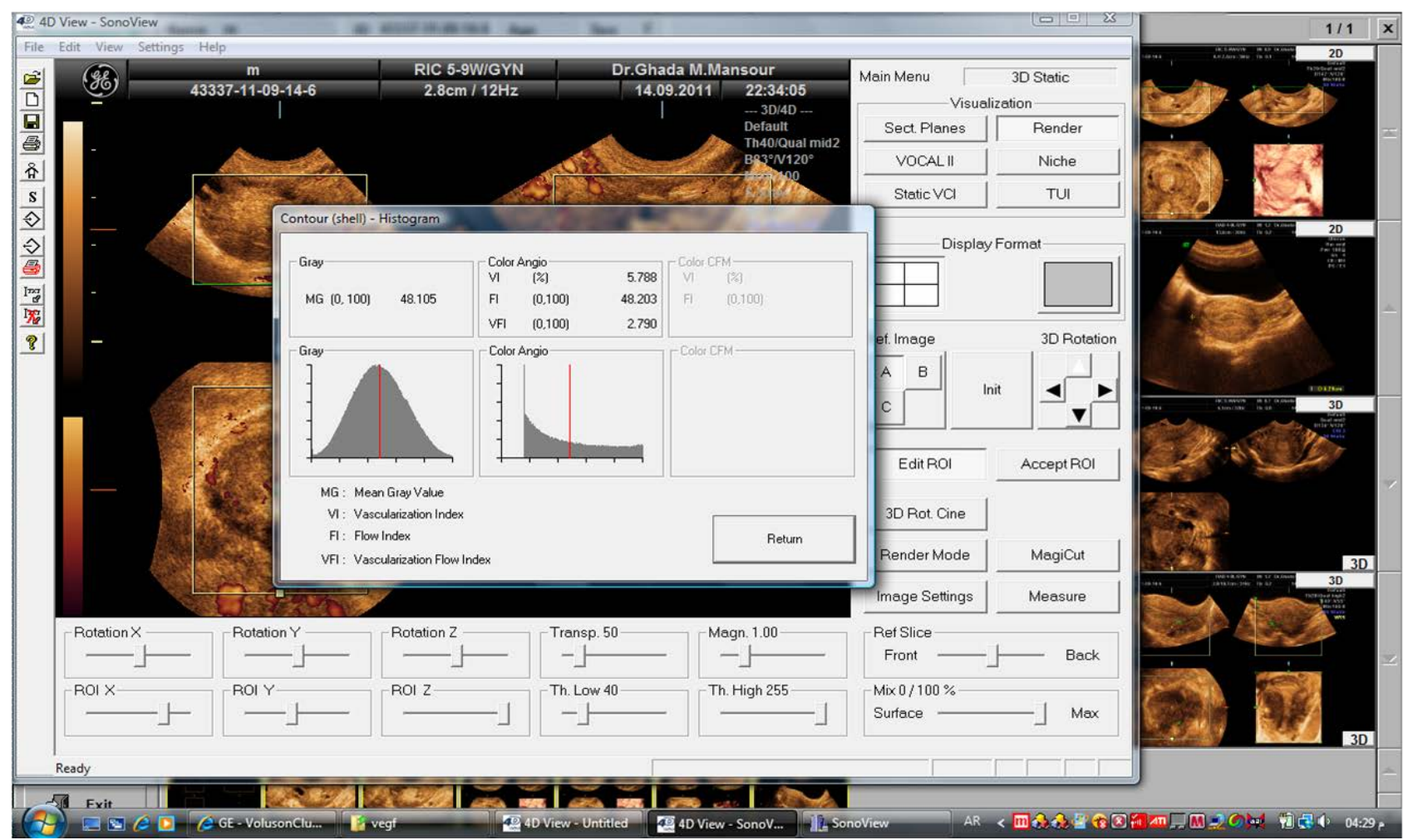

(At the right side, the picture of mass and 3D mltiplanar view, and pictures of the uterus for the same case and coronal plane of endometrium at the right bottom of the picture, all are the items of the scan for every case).

Figure 1. Activation of histogram after volume acquisition and 3DPD vascular indices (VI, FI and VFI). 
Serum VEFG was measured in one hundred normal women as controls.

Statistical analysis of all results was performed using the SPSS software version 15.0 (SPSS Inc., Chicago, IL, USA). Continuous variables were presented as mean and $95 \%$ confidence interval (CI). The student's t test and the $\chi^{2}$ test were used for comparing continuous and categorical variables, respectively.

\section{RESULTS}

Final ovarian pathology revealed seventy three 73 malignant ovarian masses and seventy seven 77 were benign.

Histopathological results of benign and malignant histopathological results are shown in Tables 1 and 2.

(Ovarian ectopic pregnancies, functional cysts, Theca lutein cysts and cases of pelvic adhesions were not included in the study).

Mean age of benign cases was $37.0 \pm 2.4$ years, malignant cases $58.9 \pm 6.3$ years and controls $41.1 \pm 5.2$ years.

Serum VEGF means were $60.49 \pm 8.03,218.22 \pm$ 75.48, $601 \pm 235.33 \mathrm{pg} / \mathrm{ml}$ in controls, benign and malignant cases successively with highly significant differences between all groups (Table 3).

Twelve malignant cases with ascites had a mean serum VEGF level of $801.08 \pm 12.03 \mathrm{pg} / \mathrm{ml}(670-1225$ $\mathrm{pg} / \mathrm{ml}$ ). The presence of ascites was associated with a significantly higher serum VEGF levels.

Means and ranges of RI, VI, FI and VFI, and serum CA125 in IU/ml are mentioned in Table 4.

The difference in mean RI, VI, FI, VFI and CA125 in benign and malignant cases were tested using $t$ test, malignant cases showed statistically lower mean RI, higher mean VI, FI, VFI, and CA 125 when compared to benign cases $\mathrm{p}<0.001$ (Table 4).

Correlation coefficient test revealed a positive correlation between VEGF and VI, positive correlation between VEGF and FI, positive correlation between VEGF and VFI and negative correlation between VEGF and RI (Table 5, Figures 2-7).

Table 1. Histopathological results of malignant masses.

\begin{tabular}{cc}
\hline Pathological results & Number \\
\hline Serous cystadenocarcinoma & 43 \\
Mucinous cystadenocarcinoma & 12 \\
Clear cell carcinoma & 8 \\
Endodermal sinus tumor & 5 \\
Dysgerminoma & 2 \\
Sertoli-Leydig cell tumor & 2 \\
Krukenberg & 1 \\
Total & 73 \\
\hline
\end{tabular}

Table 2. Pathological results of benign masses.

\begin{tabular}{cc}
\hline Pathological results & Number \\
\hline Serous cystadenoma & 29 \\
Mucinous cystadenoma & 23 \\
Mature cystic teratoma & 7 \\
Fibroma & 2 \\
Endometriosis & 16 \\
Total & 77 \\
\hline
\end{tabular}

The ability of VEGF to differentiate malignancy from benign masses at a cutoff VEGF level of $280 \mathrm{pg} / \mathrm{ml}$ gave a sensitivity of $76 \%$, a specificity of $70 \%$, a positive predictive value of $89 \%$, and a negative predictive value of $52 \%$.

\section{DISCUSSION}

The age-adjusted incidence rate of ovarian cancer in USA was 12.5 per 100,000 women per year. These rates are based on cases diagnosed in 2006-2010 from 18 SEER (Surveillance Epidemiology and End Results) geographic areas [5].

The age-adjusted death rate was 8.1 per 100,000 women per year. These rates are based on patients who died in 2006-2010 in the US [5].

According to SEER data, in 2011, 21,990 women were newly diagnosed cases of ovarian cancer in USA and 15,460 died. The American Cancer Society expected that in 2012, about 22,280 new cases of ovarian cancer will be diagnosed and 15,500 women will die of ovarian cancer in the United States [5].

According to the data, the mortality rates for ovarian cancer have not improved in forty years since the "War on Cancer" was declared.

Other cancers have shown a marked reduction in mortality, due to the availability of early detection tests and improved treatments. Unfortunately, this is not the case with ovarian cancer, which is still the deadliest of all gynecologic cancers.

All preoperative diagnostic procedures that are able to distinguish whether an ovarian neoplasm is malignant or benign should be done for planning optimized treatment. A preoperative suggestion of malignancy can guide the gynecologist to refer women with suspected pelvic masses to an oncological unit for appropriate therapy and optimized debulking in the appropriate time [6-8].

Not only the surgical aspect but the postoperative chemotherapeutics and the expected survival rate and prognosis of the case should be widely investigated and predicted preoperative.

The current preoperative assessment of ovarian mass includes clinical criteria and investigations as tumor markers and imaging of the mass. 
Table 3. Serum VEGF levels values in $\mathrm{pg} / \mathrm{ml}$ in all groups.

\begin{tabular}{ccccccc}
\hline & N & Mean & 土SD & 95\% Confidence Interval for Mean & Minimum & Maximum \\
\hline Control & 100 & 60.49 & 8.03 & $58.90,62.08$ & 53.00 & 75.00 \\
Benign & 77 & 218.22 & 75.48 & $201.09,235.35$ & 140.00 & 310.00 \\
Malignant & 73 & 601.01 & 235.33 & $546.11,655.92$ & 320.00 & 1225.00 \\
\hline
\end{tabular}

The difference in mean VEGF in control, benign and malignant cases was tested using one-way analysis of variance. Multiple comparison were performed using Bonferroni test. There was a statistical significant difference between the three groups $\mathrm{p}<0.0001$. Benign cases showed on average 158 more than control group $\mathrm{p}<0.001$ and malignant cases showed 540 more $\mathrm{p}<0.001$, also malignant cases showed 383 higher than benign $\mathrm{p}<0.001$.

Table 4. Comparison between benign and malignant cases according to RI, VI, FI and VFI, and CA125.

\begin{tabular}{ccccccccc}
\hline & & Mean & \multicolumn{2}{c}{ 95\% Confidence Interval for Mean } & Minimum & Maximum & $\boldsymbol{t}$ & p \\
\hline \multirow{2}{*}{ RI } & Benign & 0.64 & 0.62 & 0.66 & 0.57 & 0.75 & 16.87 & $<0.0001$ \\
& Malignant & 0.45 & 0.44 & 0.46 & 0.37 & 0.60 & \\
\multirow{2}{*}{ VI } & Benign & 7.38 & 6.80 & 7.96 & 5.00 & 17.00 & 22.45 & $<0.0001$ \\
& Malignant & 17.03 & 16.40 & 17.67 & 11.00 & 22.00 & & \\
\multirow{2}{*}{ FI } & Benign & 22.40 & 21.40 & 23.41 & 17.00 & 30.00 & 23.28 & $<0.0001$ \\
& Malignant & 36.84 & 36.14 & 37.53 & 29.00 & 48.00 & & \\
\multirow{2}{*}{ VFI } & Benign & 1.42 & 1.32 & 1.52 & 0.50 & 1.90 & 28.56 & $<0.0001$ \\
& Malignant & 3.54 & 3.43 & 3.65 & 2.00 & 4.50 & & \\
CA125 & Benign & 65.81 & 52.44 & 79.17 & 25.00 & 250.00 & 9.36 & $<0.0001$ \\
& Malignant & 305.07 & 254.67 & 355.47 & 180.00 & 1100.00 & \\
\hline
\end{tabular}

The difference in mean RI, VI, FI, VFI and CA125 in benign and malignant cases were tested using t test. Malignant cases showed statistically lower mean RI, higher mean VI, FI, VFI, and CA 125 when compared to benign cases $\mathrm{p}<0.001$.

Table 5. Correlation coefficient results of VEGF versus Doppler indices.

\begin{tabular}{cccc}
\hline & \multicolumn{2}{c}{ VEGF } \\
\hline \multirow{2}{*}{ RI } & $\boldsymbol{r}$ & Benign & Malignant \\
& $\mathrm{p}$ & 0.19 & -0.16 \\
\multirow{2}{*}{ VI } & $\boldsymbol{r}$ & $\mathbf{0 . 2 8}$ & 0.19 \\
& $\mathrm{p}$ & $\mathbf{0 . 0 1 3}$ & $\mathbf{0 . 3 4}$ \\
\multirow{2}{*}{ FI } & $\boldsymbol{r}$ & $\mathbf{0 . 9 7}$ & $\mathbf{0 . 0 0 3}$ \\
& $\mathrm{p}$ & $<\mathbf{0 . 0 0 0 1}$ & $\mathbf{0 . 4 7}$ \\
\multirow{2}{*}{ VFI } & $\boldsymbol{r}$ & $\mathbf{0 . 4 7}$ & $<\mathbf{0 . 0 0 0 1}$ \\
& $\mathrm{p}$ & $<\mathbf{0 . 0 0 0 1}$ & $\mathbf{0 . 5 1}$ \\
& & & $<\mathbf{0 . 0 0 0 1}$
\end{tabular}

Pearson Correlation test: $r$ : correlation coefficient. Among cases of benign group: there was negative correlation between VEGF and RI $p=0.10$, there was a positive correlation between VEGF and VI $\mathrm{p}=0.01$ (mild association $r=0.28$ ), FI $p<0.001$ (strong association $r=0.97$ ) and VFI $p<0.001$ (moderate association $r=0.47$ ). Among case of malignant group: there was negative correlation between VEGF and RI $p=0.19$, there was a positive correlation between VEGF and VI $p=0.003$ (mild association $r=0.34$ ), and FI $\mathrm{p}<0.001$ (moderate association $\mathrm{r}=0.47$ ) and VFI $\mathrm{p}<0.001$ (moderate association $r=0.51)$.

Different scoring systems for transvaginal ultrasonographic characterization of ovarian lesions were based on visualization of the inner wall irregularities, measuring the wall thickness depicting thick septations or solid components, evaluation of the echogenicity of the lesion and analysis of the distal shadowing [9-12].

Angiogenesis has a vital role in tumor growth and metastasis, and vascular endothelial growth factor (VEGF) represents a potent cytokine in this process [13].

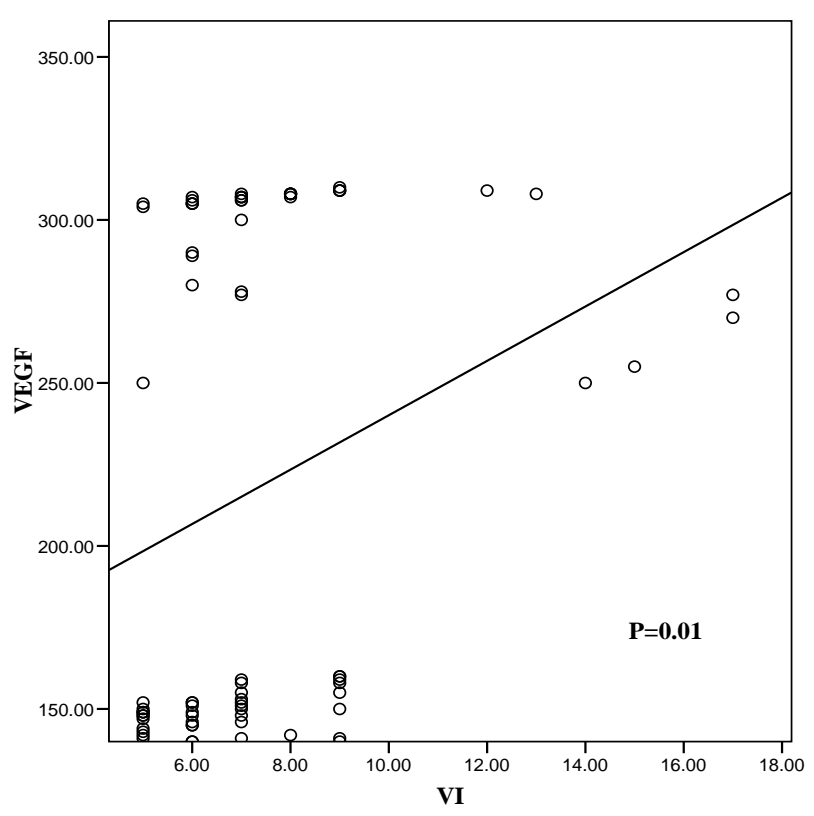

Figure 2. Scatter diagram showing the relation of VEGF and VI in benign cases.

Tumeral capillaries are devoid of muscle layer, in which resistance to blood flow is less than normal. Resistance index (RI) is a parameter used to measure resistance to blood flow in these vessels. RI reflects the degree of angiognesis in tumors. It was suggested to predict malignancy in ovarian masses [14].

The introduction of 3D power Doppler systems can 


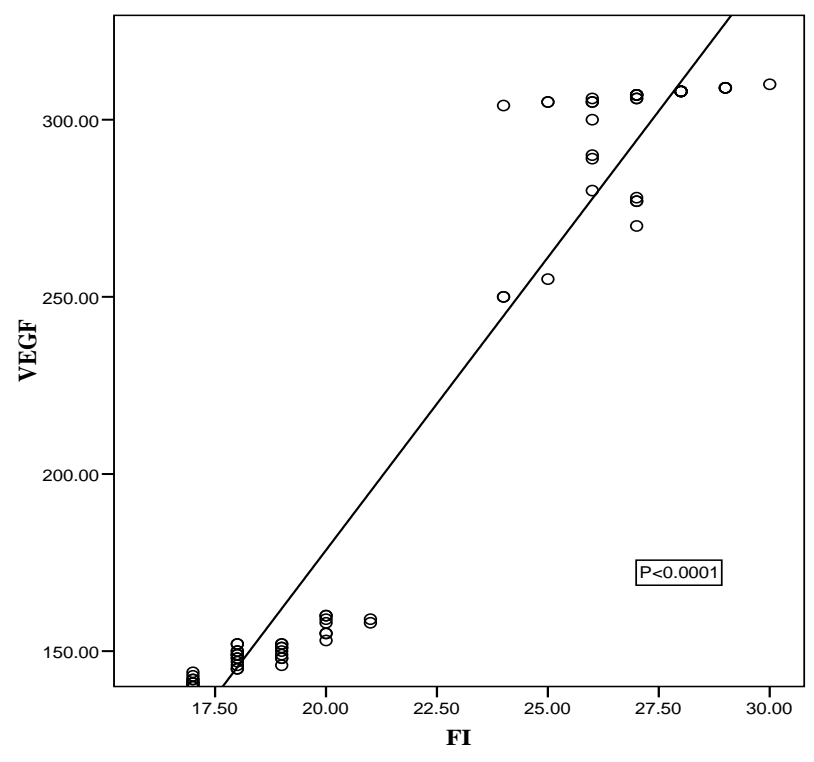

Figure 3. Scatter diagram showing the relation of VEGF and FI in benign cases.

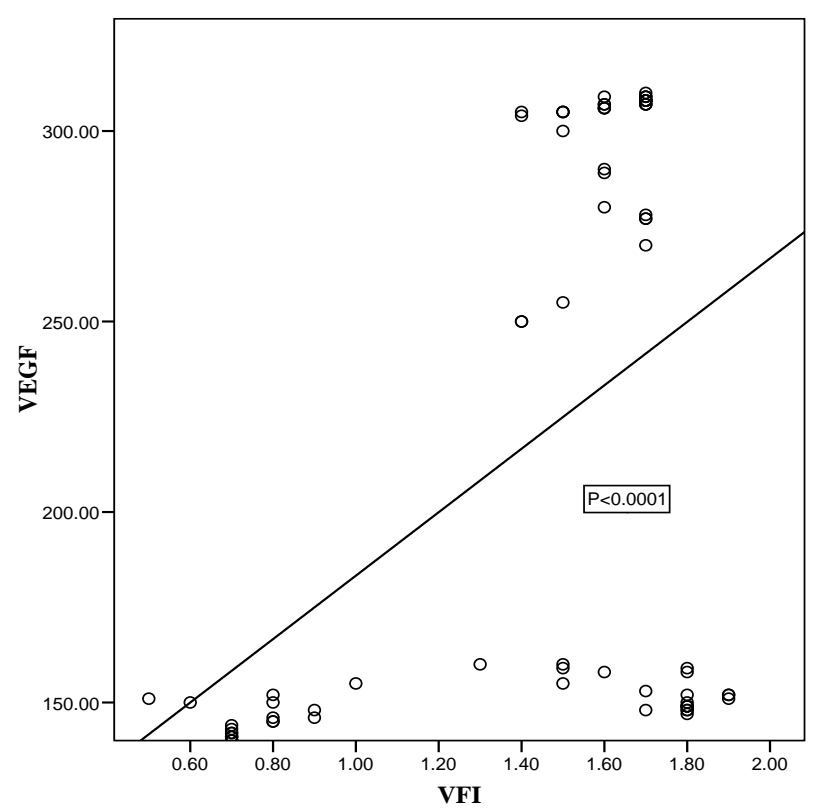

Figure 4. Scatter diagram showing the relation of VEGF and VFI in benign cases.

improve the information available on ovarian tumor vascularity; it expresses the phenomena of neoangiogenecity with malignancy. It can be of avascular, parallel or Chaotic pattern [3,4]. Vascularization index (VI), Flow index (FI) and Vascularization flow index (VFI) are the vascular indices expressing degree of angiogenesis and blood flow.

The aim of this study was to compare the serum levels of VEGF in benign and malignant ovarian masses, correlated to Doppler indices and compared to normal controls.

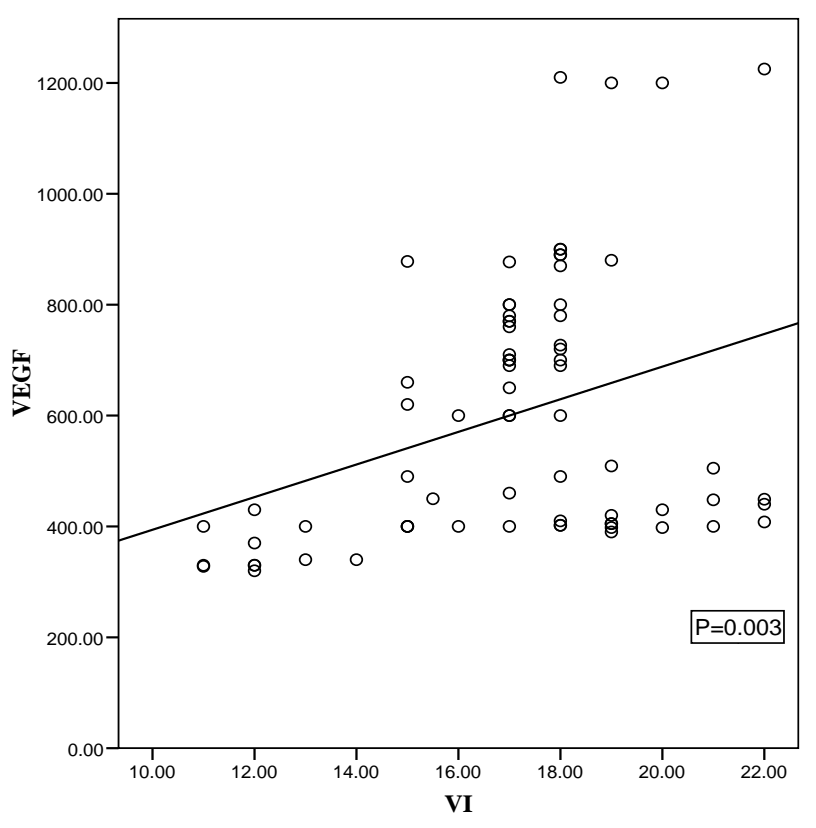

Figure 5. Scatter diagram showing the relation of VEGF and VI in malignant cases.

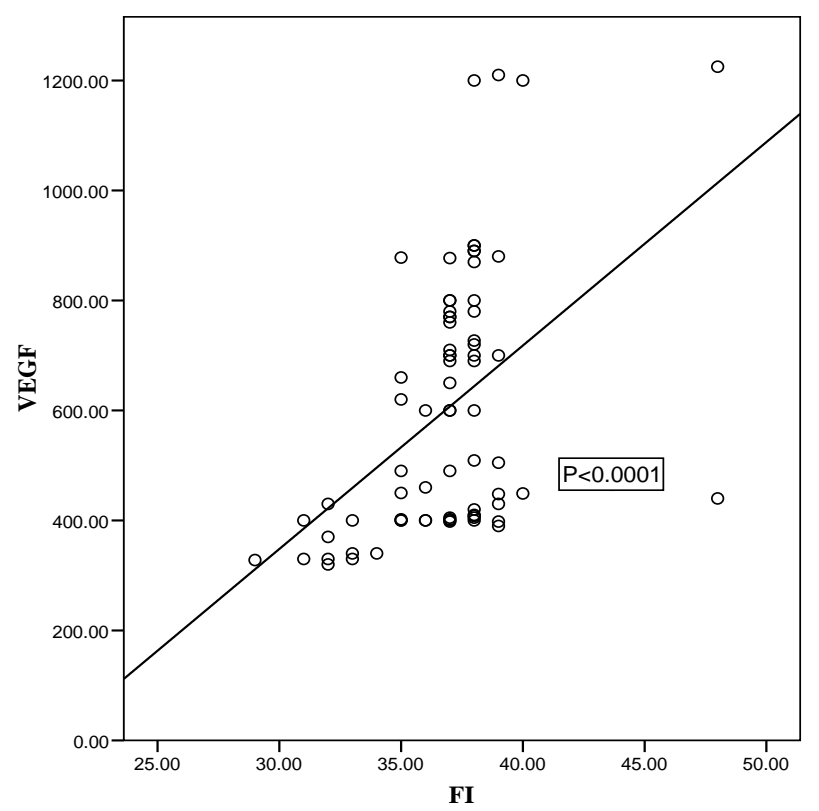

Figure 6. Scatter diagram showing the relation of VEGF and FI in malignant cases.

Final ovarian pathology revealed seventy three 73 malignant ovarian masses and seventy seven 77 were benign. Serum VEGF means were $60.49 \pm 8.03,218.22 \pm$ 75.48, $601 \pm 235.33 \mathrm{pg} / \mathrm{ml}$ in controls, benign and malignant cases successively with highly significant differences between all groups.

Correlation coefficient test revealed a positive correlation between VI, FI, and VFI versus VEGF and negative correlation between VEGF and RI. 


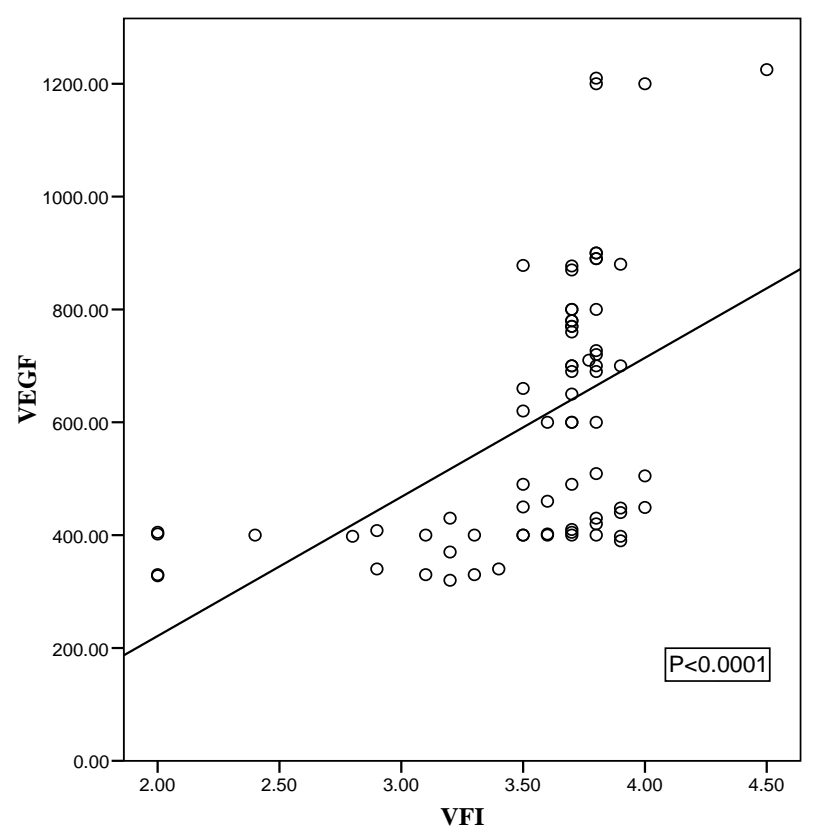

Figure 7. Scatter diagram showing the relation of VEGF and VFI in malignant cases.

The current study augmented the importance of VEGF as a diagnostic marker for malignancy which agree with many other authors [15-22]. The prognostic importance was mentioned in the literature [2,17]. In a study of Duncan et al.; they used a tissue microarray of 339 primary ovarian cancers, the expression of VEGF was assessed immunohistochemically. They concluded that high VEGF expression independently predicts poor prognosis [2]. VEGF as a prognostic marker was not discussed in the current study.

In a study of Robati, et al., to compare the diagnostic value of preoperative serum values of CA125 and VEGF, and the combination of both biomarkers for differentiating early stage epithelial ovarian cancers from ovarian cysts, the addition of VEGF to CA125 increased the sensitivity of early ovarian cancer detection from $60 \%$ to $73.3 \%$. That study indicated that the addition of VEGF serum value improves the specificity and the sensitivity of CA125 to detect early stage epithelial ovarian cancers, and to differentiate these neoplasms from ovarian cysts [15].

In another study for Cooper et al., to assess the clinical relevance of serum VEGF levels in distinguishing patients with ovarian cancer from those with benign adnexal masses, preoperative serum VEGF levels were assessed in 101 women with invasive epithelial ovarian cancer, 16 with low malignant potential (LMP) ovarian tumors, and 34 women with benign ovarian tumors, they concluded that preoperative VEGF levels may be useful in differentiating benign adnexal masses from malignancy and considered that preoperative VEGF level >380 $\mathrm{pg} / \mathrm{ml}$ is an independent risk factor for death because of disease [16]. Cut off value of the current study was 280 $\mathrm{pg} / \mathrm{ml}$ had a sensitivity of $76 \%$, a specificity of $70 \%$, a positive predictive value of $89 \%$, and a negative predictive value of $52 \%$.

In a study for Harlozinska et al., VEGF levels were significantly elevated in the sera and cyst fluids of carcinoma patients compared with patients who had benign neoplasms. The differences between VEGF values in sera and tumor effusions in relation to histological subtypes of ovarian carcinoma and FIGO stages were statistically insignificant. High VEGF levels in ascetic fluids appeared to be significantly associated with shorter disease-free survival and overall survival [17]. In the current study, the higher serum VEGF levels were also found in ovarian malignancy while no intra cystic fluid assessment was done in the current study. In a study of Demirkiran et al., needle puncture for cyst fluid aspiration were performed on 88 cystic ovarian masses intraoperative. Forty-five patients with benign and 43 patients with malignant ovarian pathology were analyzed for cyst fluid and serum VEGF concentrations. They concluded that there were significantly higher concentrations of VEGF present in cyst fluid and serum of patients with malignant ovarian cysts compared with benign ovarian ones [18].

Hu et al. mentioned that VEGF has its role not only in tumor angiogenesis but also vascular leakage leading to ascites [13]. That may explain the higher serum VEGF levels in cases with ascites in the current study, the presence of ascites was associated with a significantly higher serum VEGF levels. Twelve malignant cases with ascites had mean serum VEGF level of $801.08 \pm 12.03 \mathrm{pg} / \mathrm{ml}$. (670 - $1225 \mathrm{pg} / \mathrm{ml})$.

In the current study, correlation coefficient test revealed a positive correlation between VI, FI, and VFI vesrus VEGF and negative correlation between VEGF and RI.

VI, FI and VFI are expressing the degree of vascularization of an area by 3D ultrasound, while RI measures the resistance to blood flow in arteries feeding the tumor. That explain the increased levels of serum VEGF with positive correlations with 3DPD indices while there was an inverse correlation found with RI.

In an interesting study by Lutgendorf et al., they studied the relation between psychological element and preoperative VEGF serum levels in patients with ovarian cancer; they found that, women with ovarian carcinoma who reported higher levels of social well being, greater support from friends and neighbors and less distance from friends had lower levels of VEGF. Individuals who reported greater helplessness or worthlessness had higher VEGF levels, but depression as a whole was not related to VEGF levels.

Higher levels of social well being were correlated with lower VEGF levels in pre surgical patients with ovarian carcinoma. These findings suggest a possible mechanism 
by which poor social support may be associated with disease progression [20]. Although that issue was not discussed in the current study, but it should be stated that the cases were recruited from maternity hospital of Ain shams university, middle to low social classes and most patients especially the older ones did not have enough social life or friends around most of the time, however no solid data can be elicited to have a complete comment concerning social issue and its relation to VEGF in the current study.

A study of Mu et al., augmented the promising role of antiangiogenic drugs in ovarian masses and hence using the serum levels of VEGF in monitoring the patients' response to treatment [22].

In the current study, the fact that 3DPD indices correlated positively with the serum levels of VEGF is an indicator of the degree of vascularity of the mass and at the same time the serum level of VEGF. It is expected that the higher the indices values, the worse is the prognosis of the malignant mass.

3DPD as a non invasive accepted investigation can express the degree of vascularity as they correlated positively with serum VEGF.

Hence the importance of the 3D power Doppler indices which may be used as a preoperative complementary investigation to predict prognosis in such cases, and even in non operable cases of ovarian cancer if under antiangiogenic drugs, Doppler indices follow up may be used for monitoring the response of the cases to anti angiogenic drugs.

Ovarian cancer used to be the silent killer for women for many years; the late diagnosis is still a real problem. Proper diagnosis, management and using every tool to help in monitoring the postoperative condition are targeted.

Until a day that cancer may be a curable disease, all efforts to find better diagnostic facilities, predictive and prognostic procedures should be done.

\section{CONCLUSIONS}

Preoperative serum VEGF revealed higher levels in malignant ovarian masses than benign conditions and normal controls. These levels positively correlated with the Doppler vascular indices of the masses.

Considering the pilot nature of the study, further studies with larger numbers should be considered.

\section{CONFLICTS OF INTERESTS}

Authors state that there is no conflict of interest.

\section{REFERENCES}

[1] Oriel, K.A., Hartenbach, E.M. and Remington, P.L. (1999)
Trends in United States ovarian cancer mortality, 19791995. Obstetrics \& Gynecology, 93, 30-33. http://dx.doi.org/10.1016/S0029-7844(98)00397-4

[2] Duncan, T.J., Al-Attar, A., Rolland, P., Scott, I.V., Deen, S., Liu, D.T., Spendlove, I. and Durrant, L.G. (2008) Vascular endothelial growth factor expression in ovarian cancer: A model for targeted use of novel therapies? Clinical Cancer Research, 14, 3030-3035. http://dx.doi.org/10.1158/1078-0432.CCR-07-1888

[3] Laban, M., Metawee, H., Elyan, A., Kamal, M., Kamel, M. and Mansour, G. (2007) Three-dimensional ultrasound and three-dimensional power Doppler in the assessment of ovarian tumors. International Journal of Gynecology \& Obstetrics, 99, 201-205. http://dx.doi.org/10.1016/j.ijgo.2007.03.027

[4] Mansour, G.M., El-Lamie, I.K., El-Sayed, H.M., Ibrahim, A.M., Laban, M., Abou-Louz, S.K., Abd Allah, M.Y., El-Mahallawi, M.N., El-Lamie, K.I. and Gad-Allah, M. (2009) Adnexal mass vascularity assessed by 3-dimensional power Doppler: Does it add to the risk of malignancy index in prediction of ovarian malignancy?: Four hundred-case study. International Journal of Gynecological Cancer, 19, 867-872.

http://dx.doi.org/10.1111/IGC.0b013e3181a8335e

[5] Howlader, N., Noone, A.M., Krapcho, M., Garshell, J., Neyman, N., Altekruse, S.F., Kosary, C.L., Yu, M., Ruhl, J., Tatalovich, Z., Cho, H., Mariotto, A., Lewis, D.R., Chen, H.S., Feuer, E.J. and Cronin, K.A., Eds. (2013) SEER Cancer Statistics Review, National Cancer Institute, Bethesda. http://seer.cancer.gov/csr/1975_2010/

[6] Manjunath, A.P., Pratapkumar, A.P. and Sujatha, K. (2001) Comparison of three risk-of-malignancy indices in evaluation of pelvic masses. Gynecologic Oncology, 81, 225229. http://dx.doi.org/10.1006/gyno.2001.6122

[7] Yuen, P.M., Yu, K.M. and Yip, S.K. (1997) A randomized prospective study of laparoscopy and laparotomy in the management of benign ovarian masses. American Journal of Obstetrics \& Gynecology, 177, 109-114. http://dx.doi.org/10.1016/S0002-9378(97)70447-2

[8] Benedet, J.L., Hacker, N.F. and Ngan, H.Y.S. (2000) Staging classifications and clinical practice guidelines of gynaecologic cancers. International Journal of Gynecology \& Obstetrics, 70, 207-312.

http://dx.doi.org/10.1016/S0020-7292(00)00300-3

[9] Jacobs, I., Oram, D., Fairbanks, J., et al. (1990) A risk of malignancy index incorporating CA125, ultrasound and menopausal status for the accurate preoperative diagnosis of ovarian cancer. British Journal of Obstetrics and Gynaecology, 97, 922-929. http://dx.doi.org/10.1111/j.1471-0528.1990.tb02448.x

[10] Davies, A.P., Jacobs, I., Woolas, R., Fish, A. and Oram, D. (1993) The adnexal mass: Benign or malignant? Evaluation of a risk of malignancy index. British Journal of Obstetrics and Gynaecology, 100, 927-931. http://dx.doi.org/10.1111/j.1471-0528.1993.tb15109.x

[11] Tingulstad, S., Hagen, B. and Skjeldestad, F.E. (1996) Evaluation of a risk of malignancy index based on serum CA125, ultrasound findings and menopausal status in the preoperative diagnosis of pelvic masses. British Journal of Obstetrics and Gynaecology, 103, 826-831. 
http://dx.doi.org/10.1111/j.1471-0528.1996.tb09882.x

[12] Andersen, E.S., Knudsen, A., Rix, P., et al. (2003) Risk of malignancy index in the preoperative evaluation of patients with adnexal masses. Gynecologic Oncology, 90, 109-112. http://dx.doi.org/10.1016/S0090-8258(03)00192-6

[13] Hu, L., Hofmann, J., Holash, J., Yancopoulos, G.D., Sood, A.K. and Jaffe, R.B. (2005) Vascular endothelial growth factor trap combined with paclitaxel strikingly inhibits tumor and ascites, prolonging survival in a human ovarian cancer model. Clinical Cancer Research, 11, 69666971. http://dx.doi.org/10.1158/1078-0432.CCR-05-0910

[14] Kidron, D., Bernheim, J., Aviram, R., Cohen, I., Fishman, A., Beyth, Y. and Tepper, R. (1999) Resistance to blood flow in ovarian tumors: Correlation between resistance index and histological pattern of vascularization. Ultrasound in Obstetrics \& Gynecology, 13, 425-430. http://dx.doi.org/10.1046/j.1469-0705.1999.13060425.x

[15] Robati, M., Ghaderi, A., Mehraban, M., Shafizad, A., Nasrolahi, H. and Mohammad, M. (2013) Vascular endothelial growth factor (VEGF) improves the sensitivity of CA125 for differentiation of epithelial ovarian cancers from ovarian cysts. Archives of Gynecology and Obstetrics, 288, 859-865.

http://dx.doi.org/10.1007/s00404-013-2819-7

[16] Cooper, B.C., Ritchie, J.M., Broghammer, C.L., Coffin, J., Sorosky, J.I., Buller, R.E., Hendrix, M.J. and Sood, A.K. (2002) Preoperative serum vascular endothelial growth factor levels: Significance in ovarian cancer. Clinical Cancer Research, 8, 3193-3197.

[17] Harlozinska, A., Sedlaczek, P., Kulpa, J., Grybos, M., Wójcik, E., Van Dalen, A. and Einarsson, R. (2004) Va-

\section{ABBREVIATIONS}

VEGF: Vascular endothelial growth factor; 3DPD: Three dimensional power Doppler; VI: Vascularization index; scular endothelial growth factor (VEGF) concentration in sera and tumor effusions from patients with ovarian carcinoma. Anticancer Research, 24, 1149-1157.

[18] Demirkiran, F., Kumbak, B., Bese, T., Arvas, M., Benian, A., Aydin, S., Uzun, H., Sanioglu, C., Aydinli, K. and Kösebay, D. (2003) Vascular endothelial growth factor in adnexal masses. International Journal of Gynecology \& Obstetrics, 83, 53-58. http://dx.doi.org/10.1016/S0020-7292(03)00208-X

[19] Tanir, H.M., Ozalp, S., Yalcin, O.T., Colak, O., Akcay, A. and Senses, T. (2003) Preoperative serum vascular endothelial growth factor (VEGF) in ovarian masses. European Journal of Gynaecological Oncology, 24, 271-274.

[20] Lutgendorf, S.K., Johnsen, E.L., Cooper, B., Anderson, B., Sorosky, J.I., Buller, R.E. and Sood, A.K. (2002) Vascular endothelial growth factor and social support in patients with ovarian carcinoma. Cancer, 95, 808-815. http://dx.doi.org/10.1002/cncr.10739

[21] Obermair, A., Tempfer, C., Hefler, L., Preyer, O., Kaider, A., Zeillinger, R., Leodolter, S. and Kainz, C. (1998) Concentration of vascular endothelial growth factor (VEGF) in the serum of patients with suspected ovarian cancer. British Journal of Cancer, 77, 1870-1874. http://dx.doi.org/10.1038/bjc.1998.311

[22] Mu, J., Abe, Y., Tsutsui, T., Yamamoto, N., Tai, X.G., Niwa, O., Tsujimura, T., Sato, B., Terano, H., Fujiwara, H. and Hamaoka, T. (1996) Inhibition of growth and metastasis of ovarian carcinoma by administering a drug capable of interfering with vascular endothelial growth factor activity. Japanese Journal of Cancer Research, 87, 963-971.

http://dx.doi.org/10.1111/j.1349-7006.1996.tb02127.x

FI: Flow index;

VFI: Vascularization flow index;

SEER: Surveillance epidemiology and end results. 